\title{
Study on Regular Inspection Frequency of Bridge Based on Seismic Vulnerability Analysis
}

\author{
Peng Sun, ${ }^{1,2}$ Fengkun Cui, ${ }^{3}$ Haiyang Qin, ${ }^{2}$ and Xiaomeng Hou $\mathbb{D D}^{1}$ \\ ${ }^{1}$ Key Lab of Smart Prevention and Mitigation of Civil Engineering Disasters of the Ministry of Industry \\ and Information Technology, Key Lab of Structures Dynamic Behavior and Control of the Ministry of Education, \\ Harbin Institute of Technology, Harbin 150090, China \\ ${ }^{2}$ School of Highway, Chang'an University, Xi'an 710064, China \\ ${ }^{3}$ Department of Transportation and Civil Engineering, Shandong Jiaotong University, Jinan 250357, China
}

Correspondence should be addressed to Xiaomeng Hou; houxiaomeng@gmail.com

Received 8 August 2018; Accepted 8 November 2018; Published 5 December 2018

Academic Editor: Hamid Toopchi-Nezhad

Copyright (c) 2018 Peng Sun et al. This is an open access article distributed under the Creative Commons Attribution License, which permits unrestricted use, distribution, and reproduction in any medium, provided the original work is properly cited.

This study introduces a method to obtain accurate results regarding bridge seismic cost and reduce structural seismic losses. A three-span reinforced concrete (RC) continuous bridges model consistent with the reality was established, and seismic vulnerability of the RC bridge was calculated via incremental dynamic analysis combined with local earthquake disaster data. Direct losses from earthquakes are calculated based on local earthquake damage condition, specific maintenance reinforcement methods, and analysis of seismic vulnerability. The indirect economic losses caused by inspection and maintenance are calculated based on local traffic volume. To reduce the effects of bridge aging and deterioration, this paper examines periodic inspection of bridges after earthquakes. By calculating the life cycle cost of structure under different inspection frequencies, the optimal time interval was determined. The results presented for this study can serve as references for the calculation of structural seismic loss and thereby provide the basis for strategies of reducing seismic loss.

\section{Introduction}

Bridges are often subjected to various events such as earthquakes, fires, and traffic accidents [1]. Earthquakes are common and can cause serious economic losses; hence, seismic risk assessment in transportation networks has become a popular research area $[2,3]$. To reduce earthquakerelated economic losses for bridges and to identify reasonable inspection and maintenance intervals, it is necessary to evaluate seismic loss precisely.

Studies related to earthquake loss assessment are generally concentrated in the field of architecture. Probability analysis can reflect the variability of ground motion parameters [4-6]; seismic loss assessment is thus evolving from deterministic parsing to probabilistic analysis. Luo et al. [7] provided a seismic loss calculation method using an RC frame structure with different seismic fortification levels based on PEER-PBEE to explore ground motion intensity, the applicable vulnerability function, and the loss function, all of which should be considered in earthquake loss evaluation. Kiremidjian et al. [8] conducted a study on direct losses resulting from bridge failure and driving delays under specific earthquake conditions. In addition, Chang et al. [9] developed a method to identify a series of seismic scenarios to estimate regional seismic intensity. Wang and Sun [10] analyzed an existing bridge's mechanical behavior and vulnerability. Zhou et al. [11] selected common earthquake damage factors and obtained the corresponding relationships between the damage grade and earthquake damage index via multiple linear regression and the least squares method. Li et al. [12] investigated and calculated cost data for a city bridge project. Mahmoud et al. [13] introduced a new double-stage static method to estimate capacity curves of MR frames; in addition to enhanced accuracy, the N1-N2 method was found to be exceptionally efficient. Only recently have the effects of bridge columns' cumulative seismic vulnerability been considered in bridges' life cycle cost analysis [14-16]. The loss ratio obtained by 
a special study was used to calculate earthquake losses of railway bridges; however, it is not accurate to calculate direct structural losses from earthquakes via the loss ratio. Establishing a model that corresponds to reality to quantify bridgerelated seismic loss remains challenging. Generally, special inspections are only carried out for bridge structures after moderate earthquakes, although earthquakes can happen at any time. It is therefore necessary to identify reasonable inspection intervals, which can be added as special inspections and significantly reduce earthquake losses.

In this paper, an accurate model and structural vulnerability curve obtained via incremental dynamic analysis (IDA) is presented. The results of direct economic structural loss after earthquakes are calculated based on seismic data at the case site, statistical analysis of various maintenance and reinforcement measures taken after the earthquake, city bridges' engineering cost data, and statistical analysis of local traffic information to calculate indirect economic losses after earthquakes. Assumptions for regular inspection and maintenance activities include 1-, 2-, 3-, 4-, and 5-year time intervals and calculating the cost of a bridge at every interval in its service life to determine the optimal inspection interval.

\section{Methods}

The first step in assessing seismic loss to determine the optimal inspection frequency is to identify the seismic parameters, source characteristics of earthquakes, and types of earthquakes throughout history in the region. Seismic hazard analysis follows from identifying the magnitude and frequency of earthquakes in a region over a certain period of time $[4,9,17]$. Then, fragility curves can be obtained by analyzing seismic vulnerability of structure [18-20]. For a specific earthquake intensity, the probability of a structure being in various states of damage after an earthquake can be determined using fragility curves. The second step is statistical analysis of repair strategies, preferably those associated with different damage states, such as strategies' unit cost, and traffic information (average daily traffic, downtime associated with different damage levels, and so on). An increase in the damage state can reduce the link traffic capacity and speed limit, resulting in additional travel time. The amount of traffic volume that exceeds the capacity of the damaged link has to follow the detour [21]. Next, it is necessary to compute the direct and indirect losses of the affected structure associated with the bridge's damage state to calculate the cost of routine maintenance and inspection at certain intervals in the bridge's service life. Finally, to determine the optimal inspection interval, overall performance requirements must be satisfied while the total resource costs remain stable. A flow chart summarizing this methodology is presented in Figure 1.

\section{Bridge Modeling}

The bridge in this study is designed for continuous $\mathrm{T}$ girder with a total length of $3 \times 25 \mathrm{~m}$, four traffic lanes, and a bridge width of $21 \mathrm{~m}$. The main beam is composed of seven $\mathrm{T}$ beams made of concrete C40 (see Figure 2). Static and dynamic analyses of the structure were carried out in OpenSees (http:// opensees.berkeley.edu/) to evaluate the comprehensive performance of the postearthquake bridge. The bent cap should be designed as a capability protection component [22], and the $\mathrm{T}$ girder and bent cap are modeled using linear elastic beam-column elements.

The pier is a double-column pier with a diameter of $1.4 \mathrm{~m}$, a height of $10 \mathrm{~m}$, and C30 material (see Figure 3), which is modeled by a nonlinear three-dimensional beamcolumn element. The concrete cross section is discretized into several fibers. Each longitudinal reinforcement is discretized into a fiber. Thirty steel fibers of unconfined concrete are radially divided into 2 layers; there are 16 portions in the ring for a total of 32 nonconstrained concrete fibers. Constrained concrete is radially divided into 10 layers, and the ring is further divided into 16 portions (cf. Figure 2). The moment-curvature relationship of the column cross section is also represented in Figure 2. The columns on pile cap are supported by driven pile foundations with a length of $10 \mathrm{~m}$. The pier-to-deck connection is a plate-type elastomeric bearing, which is modeled by an elastomeric bearing element [23].

The abutment is supported by the pile foundation. The total height of the abutment is $9.7 \mathrm{~m}$, the height of the back wall is $2.2 \mathrm{~m}$, the depth of the reinforced concrete rocksocketed pile is $8.5 \mathrm{~m}$, and the pile diameter is $1.5 \mathrm{~m}$. Interaction between abutment and backfill is considered via the hyperbolic force-displacement (HFD) model [24]. The HFD abutment model is simulated by Hyperbolic Gap Material in OpenSees. And the parameters of the HFD abutment model are based on the study of Wilson [25]. The piles are modeled by a linear elastic beam-column element, and the soil-structure interaction is simulated via equivalent soil springs with linear behavior [26]. The abutment is connected to the deck by a lead rubber bearing [23]. The piers are most likely to be damaged under earthquake excitation. In this paper, the seismic losses of the piers after an earthquake are calculated accurately. Other components can be calculated with reference to the piers.

\section{Seismic Vulnerability Analysis}

4.1. Seismic Hazard Curve. Seismic hazard is the size and frequency of seismic action to which a region may be subjected for a certain period of time. The curve reflects the seismic parameters, source characteristics, and types of earthquakes in the region. The results of the seismic hazard analysis are shown in Table 1 and Figure 4.

When selecting different functions in MATLAB to fit the data in Table 1, the error of logistic regression in Table 1 was smaller, and the fitting formula was simple. The curve and function expression of the earthquake hazard are shown in Figure 4.

4.2. Probabilistic Seismic Vulnerability Analysis. When conducting a vulnerability analysis of the pier under earthquake conditions, the column's curvature ductility is used as the damage index of the structure during an earthquake based 


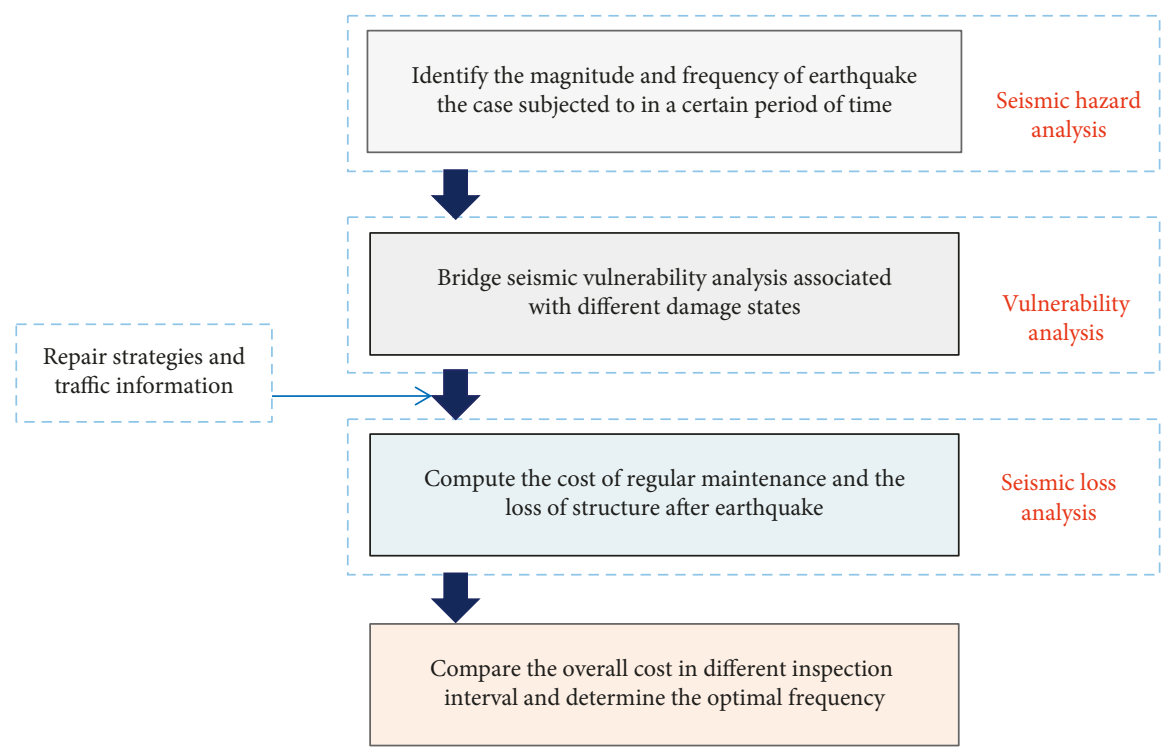

Figure 1: Method of assessing optimal regular inspection frequency.

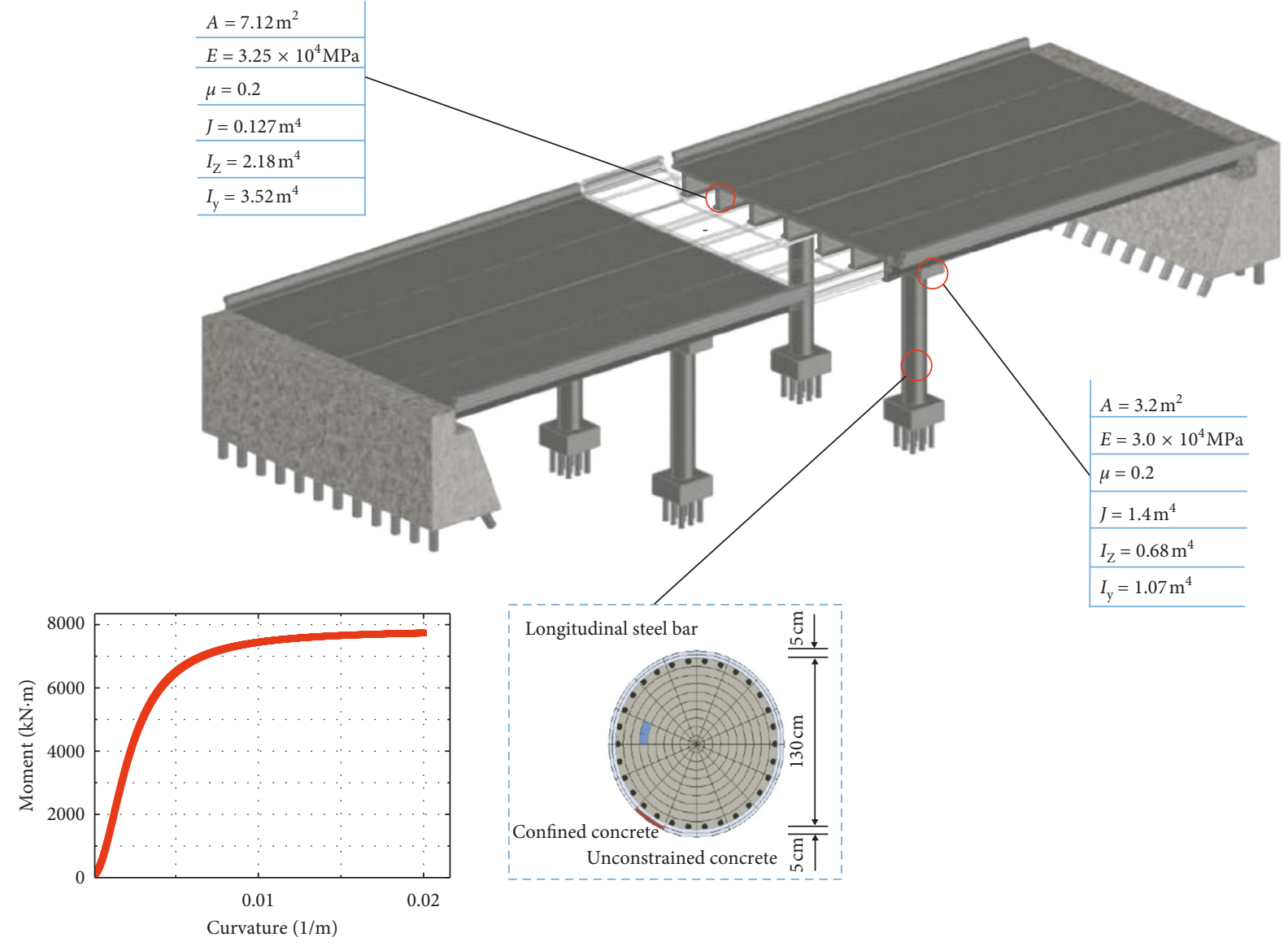

FIgURE 2: Schematic view of the bridge under study.

on the procedure given by Aryan and Ghassemieh [27]. The curvature ductility is defined as the ratio of the maximum column curvature recorded from a nonlinear time-history analysis to the column yield curvature obtained from moment-curvature analysis (Figure 5) [28]. The current paper defines four damage states based on the following [29]: slight damage, $s=1$; moderate damage, $s=2$; major damage, $s=3$; and complete damage, $s=4$. The damage limit states are assumed to equal the ductility of 1.0, 2.0, 4.0, and 7.0 for slight, moderate, major, and complete damage states, respectively 


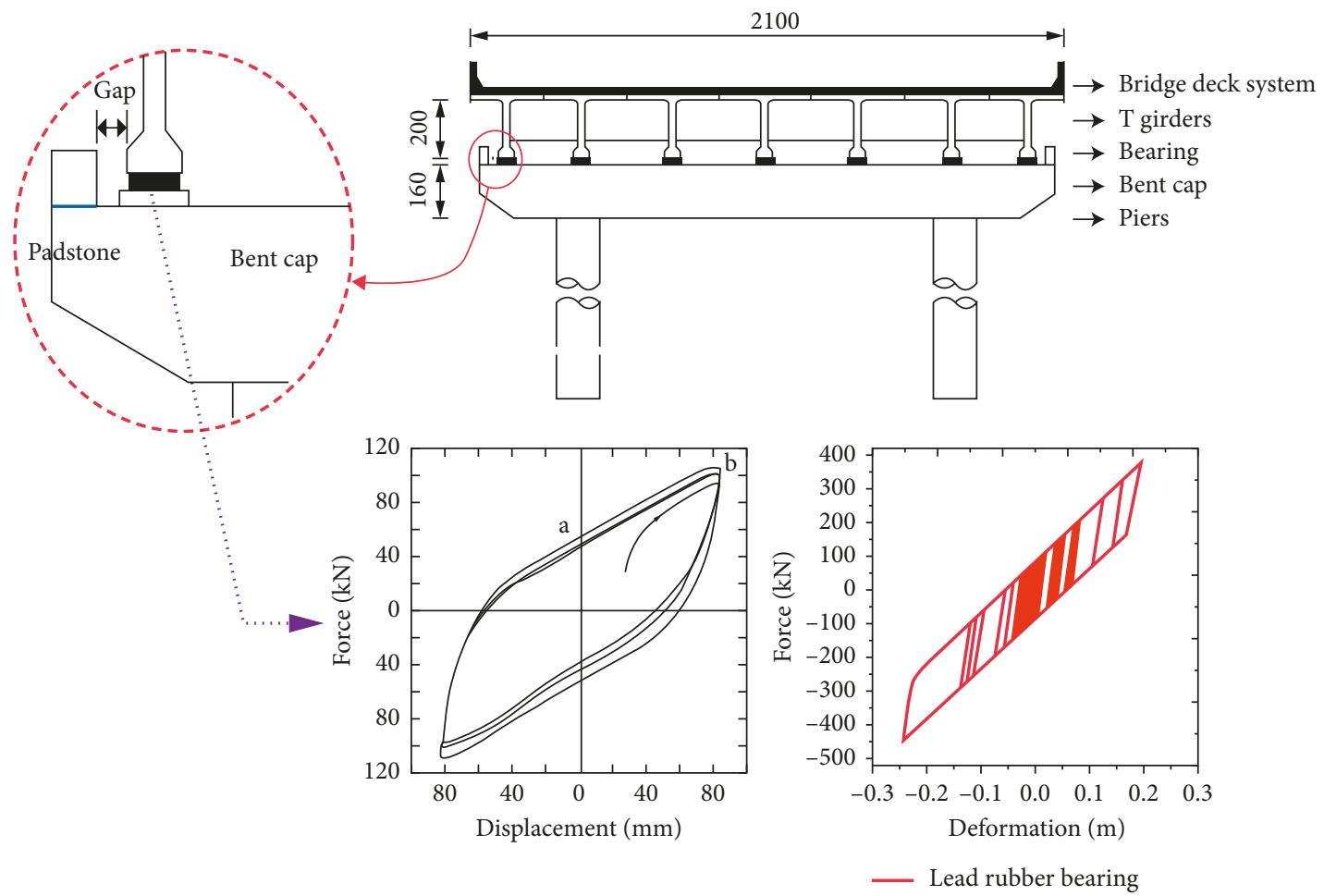

Figure 3: Composition of the pier nonlinear system.

TABle 1: Peak ground acceleration and probability of exceedance.

\begin{tabular}{lcccccccccccc}
\hline PGA & 0 & 0.01 & 0.1 & 0.13 & 0.16 & 0.22 & 0.32 & 0.4 & 0.48 & 0.6 & 0.8 & 1 \\
\hline Probability & 1 & 1 & 0.9 & 0.8 & 0.6 & 0.4 & 0.26 & 0.16 & 0.1 & 0.08 & 0.05 & 0.001 \\
\hline
\end{tabular}

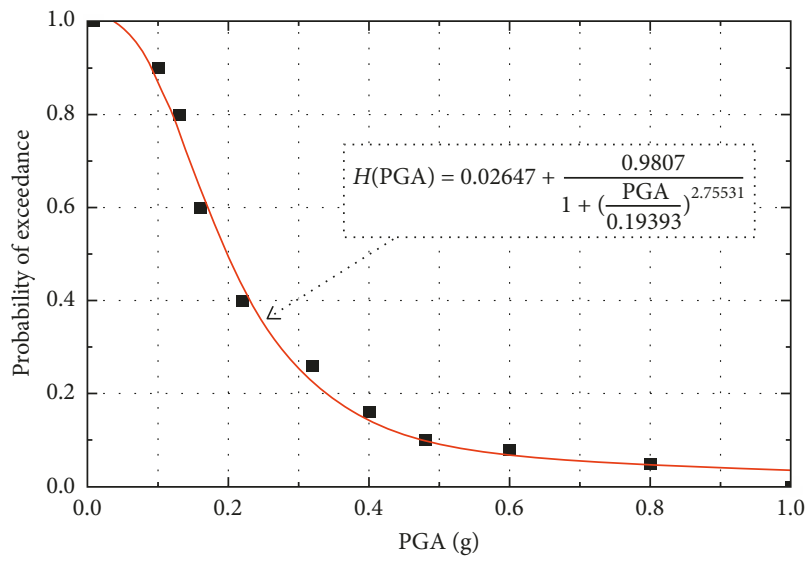

- Probability of exceedance Seismic hazard curve

FIgURE 4: The seismic hazard curve in the region.

[28]. Selecting 50 seismic waves from Appendix A of the literature [30], when scaling the PGA of each seismic wave to $0 \sim 1.5 \mathrm{~g}$, the step length is $0.1 \mathrm{~g}$ [31-33], and the bridge structure is analyzed via the IDA method. The time-history response of the pier curvature is recorded. For every working condition, the pier's top section has 50 time responses corresponding to the seismic waves; it only draws the curvature response diagram of the pier's top section under the action of two seismic waves that are limited in space (cf. Figure 5). Based on the statistical characteristics of the dynamic response of the structure under different seismic waves, the curvature distribution of piers at the corresponding peak acceleration is obtained. Here, we give the case of PGA $=0.5 \mathrm{~g}, 1.0 \mathrm{~g}$, and $1.5 \mathrm{~g}$ (Figure 5). Then, the damage to the structure is judged according to the defined damage level. If the total number of seismic waves is $N$, and the number of seismic waves to which the curvature of the pier is subjected exceeding the specified damage index is $n$, then the failure probability under the specified damage level can be obtained as follows [34]:

$$
P_{\mathrm{f}, \mathrm{s}}=P_{\mathrm{s}}(\mathrm{DS}>s \mid x)=\frac{n}{N}
$$

The vulnerability curve can be obtained after obtaining the failure probability of each damage level, but the vulnerability curve is a wave line that is not smooth. Fitting correction for the vulnerability curve via logarithmic normal cumulative distribution (Formula (2)) and seismic vulnerability curves for specific peak ground acceleration [35] is shown in Figure 5. 


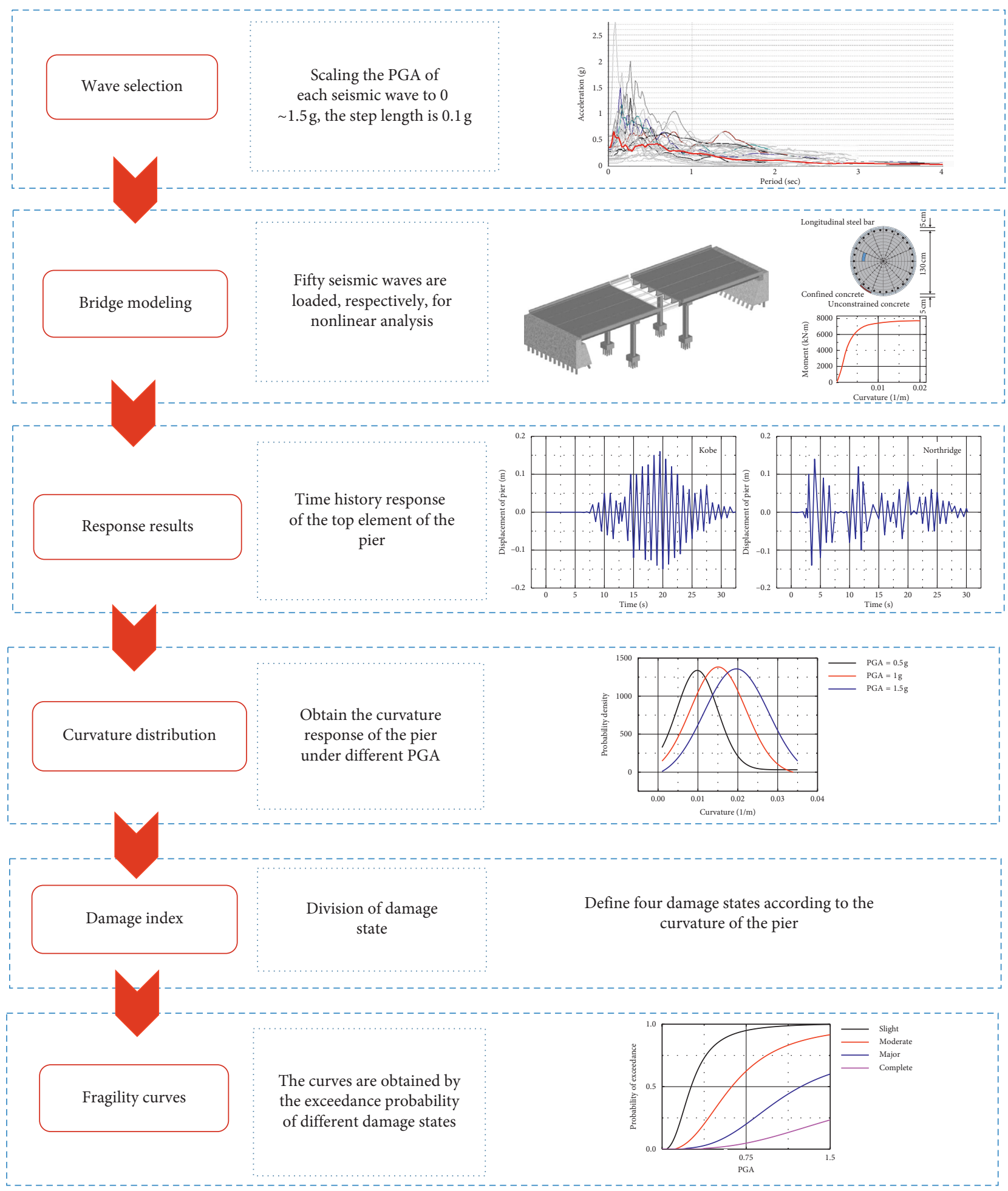

FIGURE 5: The flow chart of vulnerability analysis based on nonlinear dynamic analysis.

$$
P_{\mathrm{f}, \mathrm{s}}=\Phi\left[\frac{\operatorname{In}(\mathrm{PGA})-\operatorname{In}\left(\operatorname{med}_{\mathrm{s}}(t)\right)}{\operatorname{disp}_{\mathrm{s}}(t)}\right]
$$

where $\operatorname{med}_{\mathrm{s}, \mathrm{m}}(t)$ and $\operatorname{disp}_{\mathrm{s}, \mathrm{m}}(t)$ are the median value and logarithmic standard deviation of PGA associated with a damage state, respectively, and $\Phi(\cdot)$ is the standard normal cumulative distribution function. To avoid any intersection, the fragility curves in different damage states result in different deviation values, and Zhang and Huo [36] suggested considering a common deviation value for all damage states. In this study, the median value of logstandard deviations (equal to 0.58) is selected as the identical log-standard deviation as shown in Table 2. 
TABLE 2: The parameters of vulnerability curve under different damage states.

\begin{tabular}{lcccc}
\hline Damage state & Slight & Moderate & Major & Complete \\
\hline $\begin{array}{l}\text { Median } \\
\text { Logarithmic standard }\end{array}$ & 0.39 & 0.76 & 1.64 & 2.47 \\
deviation & 0.58 & 0.58 & 0.58 & 0.58 \\
\hline
\end{tabular}

\section{Earthquake Loss Assessment}

5.1. Calculation of Earthquake Loss. Assuming that the life of a bridge is 100 years, the frequency of inspection and maintenance is $1,2,3,4$, and 5 years, and the life cycle cost of bridges under earthquake conditions is calculated, respectively. The life cycle cost of the bridge includes routine inspection and maintenance costs at certain time intervals $\left(C_{\mathrm{e}}\right)$ and the costs associated with different damage states of the bridge subjected to earthquakes $\left(C_{\mathrm{re}}\right)$. The mentioned costs represent the major seismic costs of the bridge from project completion to the end of its service lifetime and can be calculated as [28]

$$
C_{\mathrm{t}}=C_{\mathrm{in}}+C_{\mathrm{m}}+C_{\mathrm{m}}^{\mathrm{r}}+C_{\mathrm{rep}}+C_{\mathrm{rep}}^{\mathrm{r}}
$$

where $C_{\mathrm{in}}$ is inspection cost and $C_{\mathrm{m}}$ is maintenance cost. $C_{\mathrm{m}}^{\mathrm{r}}$ is indirect cost of the maintenance procedure, including detour cost $C_{\text {run }}^{\mathrm{m}}$ and a time loss for users and goods $C_{\mathrm{tl}}^{\mathrm{m}}$ when traveling and $C_{\text {rep }}$ is direct postearthquake cost. $C_{\text {rep }}^{\mathrm{r}}$ is indirect postearthquake cost, including detour cost $C_{\text {run }}$ and a time loss for users and goods $C_{\mathrm{tl}}$ when traveling. The recurrent costs are combined by weighting them using a discount factor, $z(t)=(1+\mathrm{r})^{t}$, that takes into account the time value of money [28], and $r$ represents the after-inflation risk-free discount ratio to convert future costs into present values; in this article, $r$ assumes to be $5 \%$.

If the time interval of regular inspection and maintenance activities is 1 year, then the process of calculating structural earthquake loss is shown in Figure 6. The direct cost of regular inspection and maintenance calculated by the function in Figure 6 is $¥ 560160$. Traffic restrictions are required in the process of bridge maintenance and reinforcement, as users are forced to detour [21]. The detour cost can be calculated as follows (based on Stein et al. [6]):

$$
\begin{aligned}
C_{\text {run }}^{\mathrm{m}}(t)= & { }_{i=1}^{n}\left[c_{\mathrm{car}}\left(1-\frac{T_{i}}{100}\right)+c_{\text {truck }} \frac{T_{i}}{100}\right] \\
& * D_{i} * \mathrm{ADT}_{i} * d_{\mathrm{m}} * b_{\mathrm{m}} * z(i \Delta t),
\end{aligned}
$$

where $c_{\text {car }}$ and $c_{\text {truck }}$ are the average costs for running cars and trucks per unit length, respectively, $\mathrm{ADT}_{i}$ is the daily traffic volume of the bridge in the $i$ interval, $T_{i}$ is the average daily truck traffic ratio in the $i$ interval, and $D_{i}$ is the length of the detour. $d_{\mathrm{m}}$ is the downtime caused by maintenance, and $b_{\mathrm{m}}$ is index of usage disruption. In the current study, only $1 / 4$ of a bridge was closed each time for 1 week [28]. The monetary value of time loss for users and goods while traveling can be expressed as (based on You et al. [21])

$$
\begin{aligned}
C_{\mathrm{tl}}^{\mathrm{m}}(t)= & { }_{i=1}^{n}\left[c_{\mathrm{AW}} O_{\text {car }}\left(1-\frac{T_{i}}{100}\right)+\left(c_{\mathrm{ATC}} O_{\text {truck }}+c_{\text {goods }}\right) \frac{T_{i}}{100}\right] \\
& * \mathrm{ADT}_{i} * d_{\mathrm{m}} *\left[\frac{D_{i}}{S_{D}(t)}-\frac{l}{S_{0}(t)}\right] * z(i \Delta t),
\end{aligned}
$$

where $c_{\mathrm{AW}}$ is the average wage per hour, $c_{\mathrm{ATC}}$ is the average total compensation per hour, $c_{\text {goods }}$ is the time value of the goods, $O_{\text {car }}$ and $O_{\text {truck }}$ are the average vehicle occupancy for cars and trucks, respectively, $S_{0}(t)$ is the traffic speed on the undamaged bridge, $S_{D}(t)$ is the traffic speed on the roundabout line, and $l$ is the length of the bridge.

The direct loss in postearthquake costs is related to the maintenance measures taken after the earthquake. Assume that a bridge will return to its original state after each inspection and maintenance procedure without considering the effects of structural deterioration. Considering the different maintenance and reinforcement schemes, assume the seismic loss of different structural damage states is calculated accurately, and each result is multiplied by the appropriate weighting factor. The general formula for direct losses in postearthquake costs is shown in Figure 6, where $p_{i, \Delta t}$ represents the overall performance of the bridge under a specified seismic hazard risk and can be determined based on the annual probability of exceeding a given damage state [28], expressed as

$$
P_{s, i \Delta \mathrm{t}}=\int_{0}^{\infty} P_{\mathrm{s}, \mathrm{i}}(\mathrm{DS}>s \mid x)\left|\frac{d H(\mathrm{PGA})}{d(\mathrm{PGA})}\right| d(\mathrm{PGA}) .
$$

Convolved with the bridge's site-specific hazard curve, the exceedance probability of different damage states of the pier is obtained by Formula (6):

$$
\begin{aligned}
P_{\mathrm{s}} & =1, \\
t & =0.2057, \\
P_{\mathrm{s}} & =2, \\
t & =0.0596, \\
P_{\mathrm{s}} & =3, \\
t & =0.0138, \\
P_{\mathrm{s}} & =4, \\
t & =0.0033 .
\end{aligned}
$$

Through the above calculation, when the time interval of inspection and maintenance is 1 year, the cost of regular inspection and maintenance is $¥ 7005360$, the postearthquake loss is $¥ 3911367$, and the life cycle cost is $¥ 10916727$. When the regular interval of inspection and maintenance activities changes from every year to every 5 years, the results are as shown in Table 3.

5.2. Basic Parameters. The preferred repair strategies [37-42] for a pier subjected to an earthquake and the repair percentages of different strategies are shown in Table 4 .

The unit costs of different repair items can be obtained based on bridge construction costs [29], the market price of 


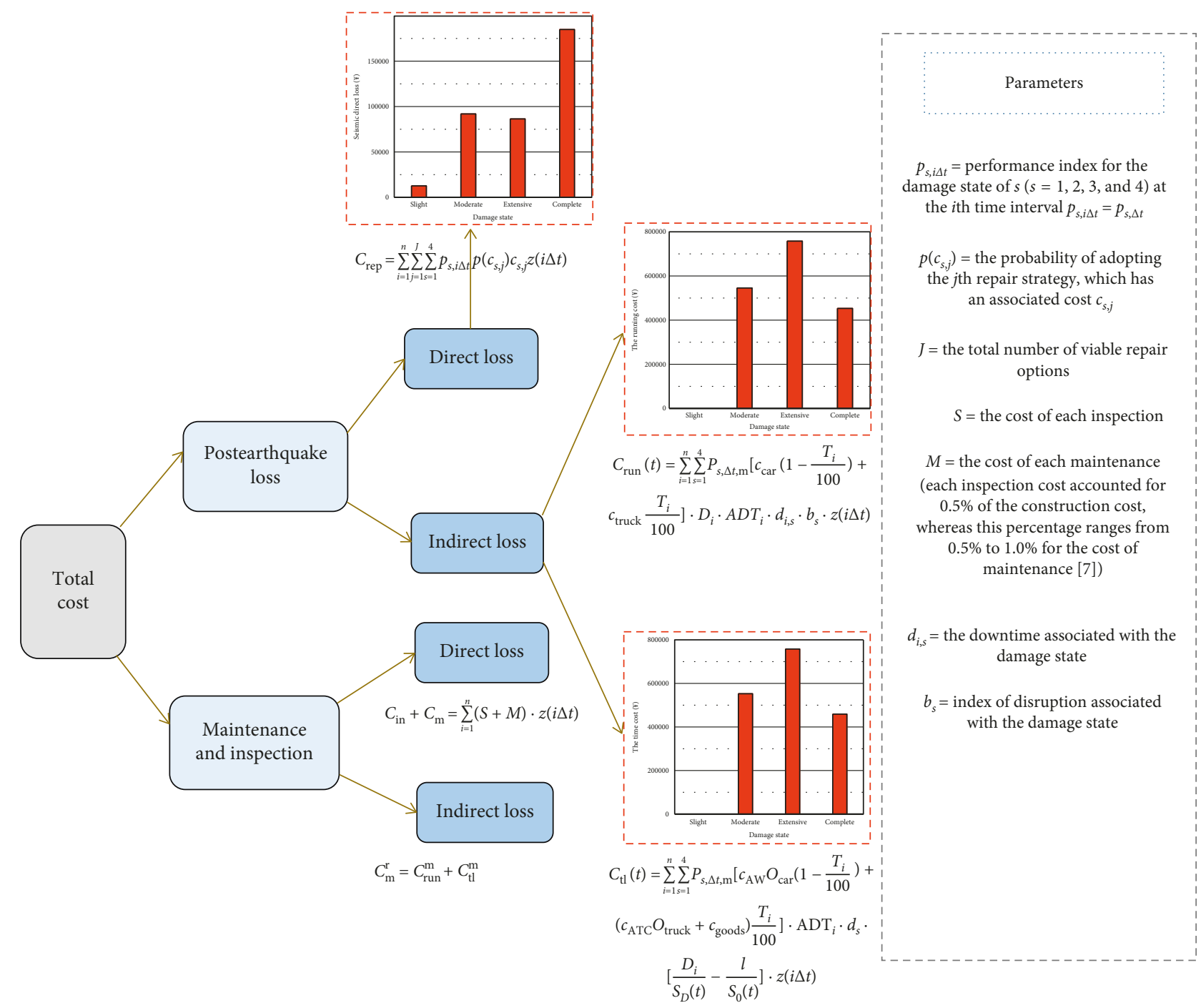

FIgURE 6: Flow chart of earthquake loss assessment.

TABLE 3: Various loss costs of structures at different time intervals.

\begin{tabular}{lccccccccc}
\hline Cost & $C_{\text {rep }}(¥)$ & $C_{\text {run }}(¥)$ & $C_{\mathrm{tl}}(¥)$ & $C_{\text {rep }}^{\mathrm{r}}(¥)$ & $C_{\mathrm{in}}+C_{\mathrm{m}}(¥)$ & $C_{\text {run }}^{\mathrm{m}}(¥)$ & $C_{\mathrm{tl}}^{\mathrm{m}}(¥)$ & $C_{\mathrm{m}}^{\mathrm{r}}(¥)$ & Total cost $(¥)$ \\
\hline 1 year & 375797 & 1756300 & 1779270 & 3535570 & 560160 & 3200000 & 3250000 & 6445200 & 10916727 \\
2 years & 375797 & 1756300 & 1779271 & 3535571 & 301000 & 1560000 & 1580000 & 3143000 & 7355368 \\
3 years & 375797 & 1756300 & 1779272 & 3535572 & 213000 & 1020000 & 1030000 & 2044700 & 6169219 \\
4 years & 375797 & 1756300 & 1779273 & 3535573 & 169000 & 743000 & 753000 & 1495920 & 5576290 \\
5 years & 375797 & 1756300 & 1779274 & 3535574 & 142000 & 580000 & 587000 & 1167300 & 5220671 \\
\hline
\end{tabular}

building materials, and the project quota of different repair strategies (Table 5) [3]. In other cases, the cost of maintenance and reinforcement should be addressed in light of actual local conditions.

The damage ratio index is assumed to be $0.03,0.08,0.25$, and 1.0 for the slight, moderate, major, and complete damage states, respectively [39-42]. For example, when the damage ratio index is 0.03 for the slight damage state, the length of the crack in the pier to be repaired is $0.03 \times 10=0.3 \mathrm{~m}$. The traffic information calculated in this region is shown in Tables 6-8.
5.3. Determination of Optimal Inspection Interval. The frequency of inspection and maintenance is 1 year, and the various loss costs of bridges under earthquake conditions are shown in Figure 7. The results of the direct and indirect structural costs in the bridge service life at different time intervals are shown in Figure 8.

As indicated, the indirect postearthquake cost and indirect maintenance cost are higher than the direct cost. The ratio of indirect postearthquake cost to direct postearthquake cost is 9.4, and the ratio of indirect cost of 
TABLE 4: Preferred repair strategies and repair percentages for the pier.

\begin{tabular}{|c|c|c|c|c|}
\hline \multirow[t]{2}{*}{ Repair strategies } & \multicolumn{4}{|c|}{$\begin{array}{c}\text { The repair percentages by damage } \\
\text { state }(\%)\end{array}$} \\
\hline & Slight & Moderate & Major & Complete \\
\hline No action & 20 & 0 & 0 & 0 \\
\hline Repair with epoxy mortar & 45 & 5 & 0 & 0 \\
\hline $\begin{array}{l}\text { Repair with epoxy fine } \\
\text { stone concrete }\end{array}$ & 20 & 23 & 0 & 0 \\
\hline $\begin{array}{l}\text { Replacement of concrete } \\
\text { protection layer }\end{array}$ & 5 & 9 & 0 & 0 \\
\hline Pasting steel plate & 5 & 18 & 0 & 0 \\
\hline Pasting carbon fiber cloth & 5 & 18 & 0 & 0 \\
\hline Replace column & 0 & 22 & 72 & 0 \\
\hline $\begin{array}{l}\text { Wrap with reinforced } \\
\text { concrete }\end{array}$ & 0 & 5 & 20 & 0 \\
\hline $\begin{array}{l}\text { Demolish and replace } \\
\text { bridge }\end{array}$ & 0 & 0 & 8 & 100 \\
\hline
\end{tabular}

TABle 5: Unit cost of different repair items used in restoration.

\begin{tabular}{lcc}
\hline Repair strategies & Unit & $\begin{array}{c}\text { Average } \\
\text { unit price }\end{array}$ \\
\hline $\begin{array}{l}\text { Repair with epoxy mortar* } \\
\text { Repair with epoxy fine }\end{array}$ & Meter & $¥ 318.42$ \\
$\begin{array}{l}\text { stone concrete* } \\
\text { Replacement of concrete }\end{array}$ & Square meter & $¥ 325.33$ \\
protection layer* & Each & $¥ 631.01$ \\
$\begin{array}{l}\text { Pasting steel plate* } \\
\text { Pasting carbon fiber cloth* }\end{array}$ & $\begin{array}{l}\text { Square meter } \\
\text { Replace column* }\end{array}$ & $¥ 843$ \\
Wrap with reinforced concrete* & Cubic meter & $¥ 601.74$ \\
Demolish and replace bridge** & Each & $¥ 27802$ \\
\hline
\end{tabular}

*Source: [22]. ** Source: [28].

TABle 6: Average daily traffic volume and detour length of the link.

\begin{tabular}{ccc}
\hline Year & Average daily traffic volume & Detour Length $(\mathrm{km})$ \\
\hline 2013 & 73750 & 2.5 \\
2014 & 77500 & 2.5 \\
2015 & 84000 & 2.5 \\
2016 & 88000 & 2.5 \\
\hline
\end{tabular}

The traffic volume of 2016 is taken as an average daily traffic volume, assuming the traffic volume does not change with time.

TABLE 7: Usage disruption and downtime associated with different damage states.

\begin{tabular}{lcc}
\hline Damage state & Usage disruption index & Downtime (days) \\
\hline Slight & $0^{\mathrm{a}}$ & $10^{\mathrm{b}}$ \\
Moderate & $0.25^{\mathrm{a}}$ & $20^{\mathrm{b}}$ \\
Major & $0.5^{\mathrm{a}}$ & $60^{\mathrm{b}}$ \\
Complete & $1^{\mathrm{a}}$ & $75^{\mathrm{b}}$ \\
\hline
\end{tabular}

${ }^{\mathrm{a}}$ Based on [28]. ${ }^{\mathrm{b}}$ Based on [30].

maintenance to the direct cost is $11.5,10.4,9.6,8.6$, and 8.2 at inspection and maintenance intervals of $1,2,3,4$, and 5 years, respectively. Routine inspection and maintenance costs are higher than postearthquake costs.
TABLE 8: Basic statistical parameters of the main variable (vehicle detour).

\begin{tabular}{|c|c|c|c|}
\hline Variables & $\begin{array}{l}\text { Estimated } \\
\text { value }\end{array}$ & Variables & $\begin{array}{l}\text { Estimated } \\
\text { value }\end{array}$ \\
\hline $\begin{array}{l}\text { Running costs } \\
\text { for cars }\end{array}$ & $0.4 ¥ / \mathrm{km}^{\mathrm{a}}$ & $\begin{array}{l}\text { Running costs } \\
\text { for trucks }\end{array}$ & $0.56 ¥ / \mathrm{km}^{\mathrm{a}}$ \\
\hline $\begin{array}{l}\text { Vehicle } \\
\text { occupancies for } \\
\text { cars }\end{array}$ & $1.5^{\mathrm{a}}$ & $\begin{array}{l}\text { Vehicle occupancies } \\
\text { for trucks }\end{array}$ & $1.05^{\mathrm{a}}$ \\
\hline $\begin{array}{l}\mathrm{ADTT} / \mathrm{ADT} \\
\text { ratio }\end{array}$ & $0.12^{\mathrm{a}}$ & Time value of a cargo & $3.81 ¥ / \mathrm{h}^{\mathrm{a}}$ \\
\hline $\begin{array}{l}\text { Wage for car } \\
\text { drivers }\end{array}$ & $23.36 ¥ / \mathrm{h}^{\mathrm{b}}$ & $\begin{array}{c}\text { Wage for truck } \\
\text { drivers }\end{array}$ & $29.28 ¥ / \mathrm{h}^{\mathrm{b}}$ \\
\hline $\begin{array}{l}\text { The traffic speed } \\
\text { on the } \\
\text { roundabout line }\end{array}$ & $80 \mathrm{~km} / \mathrm{h}^{\mathrm{b}}$ & $\begin{array}{c}\text { The traffic speed on } \\
\text { the undamaged } \\
\text { bridge }\end{array}$ & $100 \mathrm{~km} / \mathrm{h}^{\mathrm{b}}$ \\
\hline
\end{tabular}

${ }^{\mathrm{a}}$ Based on [22]. ${ }^{\mathrm{b}}$ Based on [40].

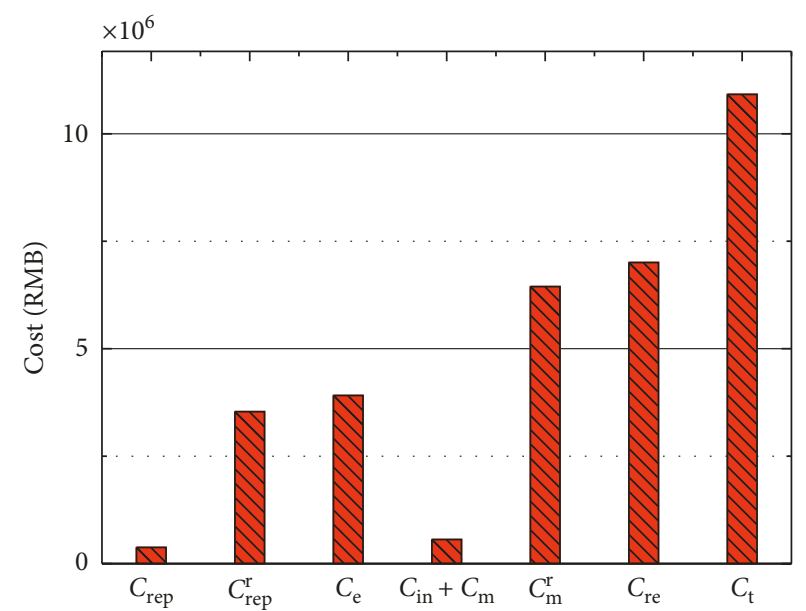

FIgURE 7: Earthquake loss at an inspection interval of 1 year.

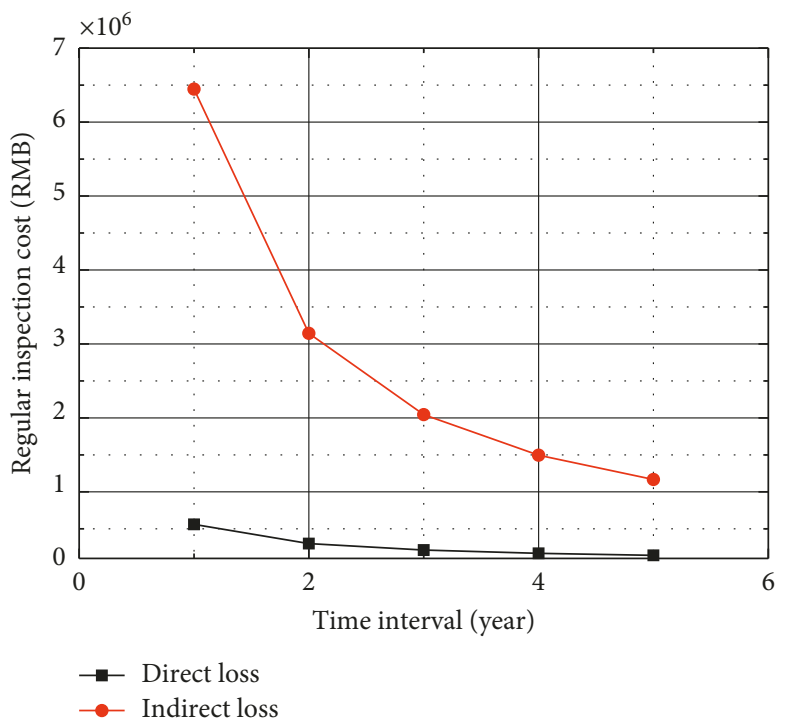

Figure 8: Regular inspection costs at different time intervals. 
Although the bridge length is short, the route is the key traffic line, and the traffic volume is large. When calculating direct postearthquake costs, the unit costs of different repair items used in maintenance represent the base price; thus, the indirect costs of maintenance are higher than the direct.

As shown above (Figures 9-10), the shorter the time interval, the higher the regular inspection cost of the structure. When the time interval changes from 1 to 2 years, the total cost is reduced significantly; when the time interval changes from 4 to 5 years, the change in total cost is not as apparent. In this case, the optimal time interval is 5 years.

\section{Conclusions}

This article presents a computational framework for the seismic vulnerability, seismic loss assessment, and frequency analysis of optimal routine bridge inspection. The optimal frequency for regular inspection is obtained based on economic metrics. Assuming the bridge will return to its original state after each maintenance procedure, seismic loss estimation is conducted via a framework based on seismic vulnerability analysis. The proposed approach also accounts for inspection and maintenance costs, uncertainty in repair procedures, and indirect losses. This methodology can be effectively used to arrive at more accurate estimates of economic losses for bridges. The seismic vulnerability of the structure is obtained by establishing an accurate model that accounts for the probability of a set of seismic scenario events that reflect earthquake activity in the region. The following conclusions are drawn:

(1) Routine inspection and maintenance are introduced to minimize loss of life and property caused by earthquakes and to reduce the effects of aging, deterioration, and corrosion. A computational framework is presented for life cycle costs at different time intervals of routine inspection, and this paper identifies an optimal frequency of regular inspection by evaluating the associated monetary values.

(2) Comparing calculated life cycle costs, it is found that as the time interval becomes larger, the total cost tends to remain stable. The most reasonable time routine inspection and maintenance interval is the minimum value of the stable value corresponding to the time interval.

(3) The information obtained from this approach can be used in maintenance and inspection procedures. The ratio of the indirect maintenance costs to direct costs is approximately 9.2; more attention can hence be paid to indirect costs.

(4) The life cycle cost is sensitive to the parameters used in earthquake loss assessment; therefore, the parameters involved in cost analysis should be estimated carefully.

(5) As the time interval grows, the effects of aging and deterioration on structures' seismic loss assessment

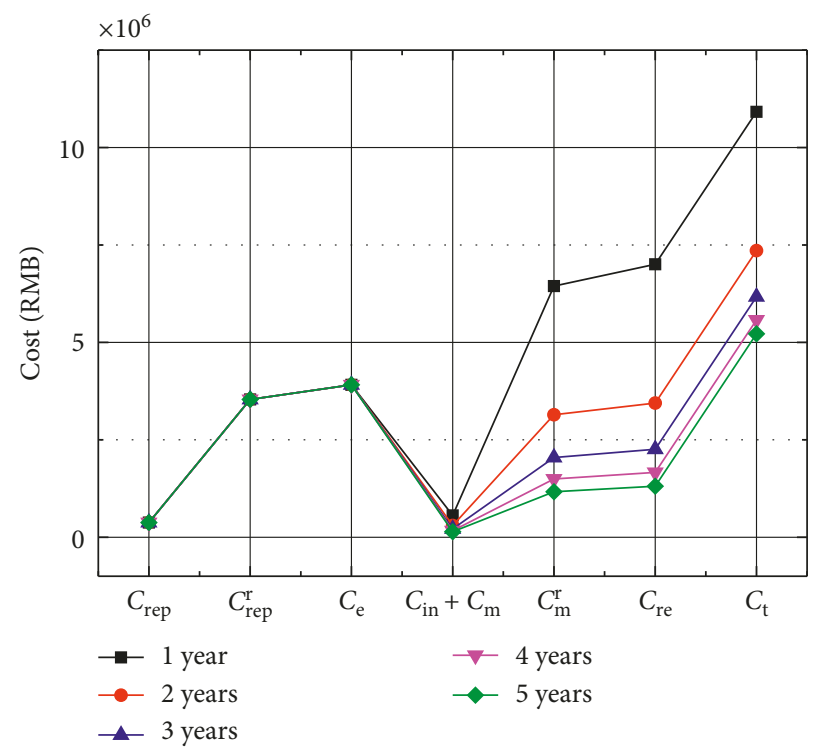

Figure 9: Various loss costs at different time intervals.

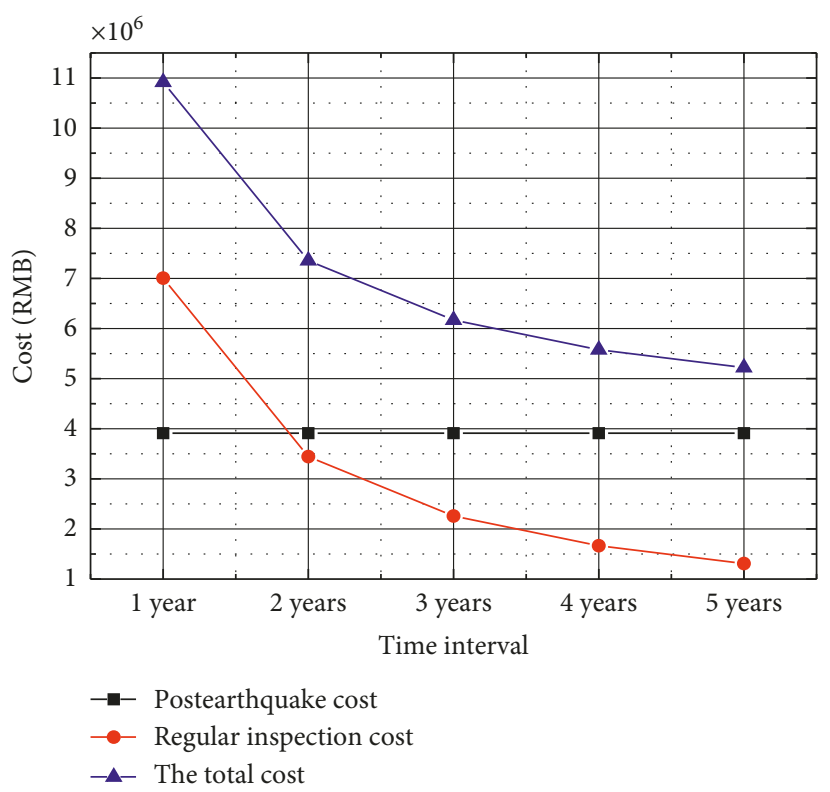

Figure 10: Total costs at different time intervals.

cannot be neglected. Future research will concentrate on time-dependent seismic vulnerability in bridge seismic loss estimation.

\section{Data Availability}

The data used to support the findings of this study are available from the corresponding author upon request.

\section{Conflicts of Interest}

The authors declare that they have no conflicts of interest. 


\section{Acknowledgments}

This work was financially supported by the National Natural Science Foundation of China (nos. 51578184 and 51408167) and the Postdoctoral Scientific Research Developmental Fund of Heilongjiang Province (no. LBH-Q15058).

\section{References}

[1] T. Michiels and S. Adriaenssens, "Form-finding algorithm for masonry arches subjected to in-plane earthquake loading," Computers \& Structure, vol. 195, pp. 85-98, 2017.

[2] X. Hou, S. Cao, R. Qin, W. Zheng, and G. Li, "Effects of steel fiber and strain rate on the dynamic compressive stress-strain relationship in reactive powder concrete," Construction and Building Materials, vol. 170, pp. 570-581, 2018.

[3] P. Bocchini and D. M. Frangopol, "Restoration of bridge networks after an earthquake: multi-criteria intervention optimization," Earthquake Spectra, vol. 28, no. 2, pp. 426-455, 2012.

[4] J. M. Andric and D. G. Lu, "Fuzzy probabilistic seismic hazard analysis with applications to Kunming city, China," Natural Hazards, vol. 89, no. 3, pp. 1031-1057, 2017.

[5] X. Hou, S. Cao, R. Qin, and W. Zheng, "A P-I diagram approach for predicting failure modes of RPC one-way slabs subjected to blast loading," International Journal of Impact Engineering, vol. 120, pp. 171-184, 2018.

[6] S. M. Stein, G. K. Young, R. E. Trent, and D. R. Pearson, "Prioritizing scour vulnerable bridges using risk," Journal of Infrastructure Systems, vol. 5, no. 3, pp. 95-101, 2017.

[7] W. Luo, Y. Li, and J. Han, "Earthquake loss estimation for RC frames based on PEER-PBEE methodology," Engineering Mechanics, vol. 33, no. 9, pp. 186-194, 2016.

[8] A. Kiremidjian, J. Moore, Y. Y. Fan, O. Yazlal, N. Basoz, and M. Williams, "Seismic risk assessment of transportation networks," Journal of Earthquake Engineering, vol. 11, no. 3, pp. 371-382, 2007.

[9] Q. P. Wang and H. Sun, "Traffic structure optimization in historic districts based on green transportation and sustainable development concept," Advances in Civil Engineering, vol. 2019, Article ID 9196263, 16 pages, 2019.

[10] X. L. Luo, L. Y. Niu, and S. G. Zhang, "An algorithm for traffic flow prediction based on improved SARIMA and GA," KSCE Journal of Civil Engineering, vol. 22, no. 10, pp. 4107-4115, 2018.

[11] C. Zhou, Q. Bai, and R. Gao, "Seismic hazard loss evaluation of railway bridge in large earthquake," Journal of Beijing Jiaotong University, vol. 37, no. 1, pp. 85-89, 2013.

[12] H. Q. Li, Y. J. Ni, X. G. Liu, and J. X. Yan, "Seismic damage analysis on the continuous girder bridge of urban rail transit line," Applied Mechanics and Materials, vol. 488-489, pp. 398-402, 2014.

[13] H. Mahmoud, A. Chulahwat, and G. Riveros, "Fatigue and fracture life-cycle cost assessment of a Miter gate with multiple cracks," Engineering Failure Analysis, vol. 83, pp. 57-7, 2017.

[14] A. Bahramirad, M. Tehranizadeh, and A. Moshref, "Equating incremental dynamic analysis with static nonlinear analysis at near-field excitation," Earthquake Engineering and Engineering Vibration, vol. 14, no. 3, pp. 465-476, 2015.

[15] X. Hou, S. Cao, W. Zheng, R. Qin, and G. Li, "Experimental study on dynamic compressive properties of fiber-reinforced reactive powder concrete at high strain rates," Engineering Structures, vol. 169, pp. 119-130, 2018.
[16] M. Liu and B. X. Mi, "Life cycle cost analysis of energyefficient buildings subjected to earthquakes," Energy and Buildings, vol. 154, pp. 581-589, 2017.

[17] J. Kiani and S. Pezeshk, "Sensitivity analysis of the seismic demands of RC moment resisting frames to different aspects of ground motions," Earthquake Engineering \& Structural Dynamics, vol. 46, no. 15, pp. 2739-2755, 2017.

[18] K. P. Guo, C. D. Zhou, L. K. Meng, and X. Y. Zhang, "Seismic vulnerability assessment of reinforced concrete silo considering granular material-structure interaction," Structural Design of Tall and Special Buildings, vol. 25, no. 18, pp. 1011-1030, 2016.

[19] J. L. Qiu, X. L. Wang, J. X. Lai et al., "Response characteristics and preventions for seismic subsidence of loess in Northwest China," Natural Hazards, vol. 92, no. 3, pp. 1909-1935, 2018.

[20] J. Lai, K. Wang, J. Qiu, F. Niu, J. Wang, and J. Chen, "Vibration response characteristics of the cross tunnel structure," Shock and Vibration, vol. 2016, Article ID 9524206, 16 pages, 2016.

[21] D. You, D. Frangopol, and D. Saydam, "Sustainability of highway bridge networks under seismic hazard," Journal of Earthquake Engineering, vol. 18, pp. 41-66, 2014.

[22] Z. Wang, E. Guo, Z. Zhao, and Q. Wang, "Analysis of gradation criterion of earthquake damage to bridges," World Earthquake Engineering, vol. 26, no. 1, pp. 90-93, 2010.

[23] W. Wen-Peng, L. Li-Feng, S. Xu-Dong, and B.-Y. Liu, "Performance-based seismic risk analysis for medium-span concrete cable-stayed bridges," China Journal of Highway and Transport, vol. 28, no. 3, pp. 52-59, 2015.

[24] A. Shamsabadi, K. M. Rollins, and M. Kapuskar, "Nonlinear soil-abutment-bridge structure interaction for seismic performance-based design," Journal of Geotechnical and Geoenvironmental Engineering, vol. 133, no. 6, pp. 707-720, 2007.

[25] P. Wilson and A. Elgamal, "Large-scale passive earth pressure load-displacement tests and numerical simulation," Journal of Geotechnical and Geoenvironmental Engineering, vol. 136, no. 12, pp. 1634-1643, 2010.

[26] O. Avsar, A. Yakut, and A. Caner, "Analytical fragility curves for ordinary highway bridges in Turkey," Earthquake Spectra, vol. 27, no. 4, pp. 971-996, 2011.

[27] H. Aryan and M. Ghassemieh, "A superelastic protective technique for mitigating the effects of vertical and horizontal seismic excitations on highway bridges," Journal of Intelligent Material Systems and Structures, vol. 28, no. 12, pp. 15331552, 2017.

[28] A. Alipour, B. Shafei, and M. Shinozuka, "Performance evaluation of deteriorating highway bridges located in high seismic areas," Jouranl of Bridge Engineering, vol. 16, no. 5, pp. 597-611, 2011.

[29] L. Jia and Z. Duan, "Structural seismic performance evaluation in consideration of earthquake ground motion uncertainties using convex set model," Advances in Structural Engineering, vol. 11, no. 3, pp. 281-291, 2008.

[30] M. Torbol and M. Shinozuka, "The directionality effect in the seismic risk assessment of highway networks," Structure and Infrastructure Engineering, vol. 10, no. 2, pp. 75-188, 2014.

[31] A. Abo-El-Ezz, C. Houalard, M. J. Nollet, and R. Assi, "Vulnerability assessment of seismic induced out-of-plane failure of unreinforced masonry wall buildings," Canadian Journal of Civil Engineering, vol. 44, no. 12, pp. 1045-1055, 2017. 
[32] O. M. O. Ramadan, S. S. F. Mehanny, and H. A. Elhowary, "Seismic vulnerability of box girder continuous bridges under spatially variable ground motions," Bulletin of Earthquake Engineering, vol. 13, no. 6, pp. 1727-1748, 2014.

[33] D. Raffaele, F. Porco, A. Fiore, and G. Uva, "Simplified vulnerability assessment of reinforced concrete circular piers in multi-span simply supported bridges," Structure and Infrastructure Engineering, vol. 10, no. 8, pp. 950-962, 2014.

[34] J. L. Qiu, X. L. Wang, S. Y. He et al., "The catastrophic landside in Maoxian County, Sichuan, SW China on June 24, 2017," Natural Hazards, vol. 89, no. 3, pp. 1485-1493, 2017.

[35] J. Ghosh and J. E. Padgett, "Aging considerations in the development of time dependent seismic fragility curves," Journal of Structural Engineering, vol. 136, no. 12, pp. 14971511, 2010.

[36] J. Zhang and Y. Huo, "Evaluating effectiveness and optimum design of isolation devices for highway bridges using the fragility function method," Engineering Structures, vol. 31, no. 8, pp. 1648-1660, 2009.

[37] J. X. Lai, S. Y. He, J. L. Qiu et al., "Characteristics of seismic disasters and aseismic measures of tunnels in wenchuan earthquake," Environmental Earth Sciences, vol. 76, no. 2, 2017.

[38] J. Ghosh and J. E. Padgett, "Probabilistic seismic loss assessment of aging bridges using a component-level cost estimation approach," Earthquake Engineering and Structural Dynamics, vol. 40, no. 15, pp. 1743-1761, 2011.

[39] A. X. Guo, Z. L. Liu, S. C. Li, and H. Li, "Seismic performance assessment of highway bridge networks considering postdisaster traffic demand of a transportation system in emergency conditions," Structure and Infrastructure Engineering, vol. 13, no. 12, pp. 1523-1537, 2017.

[40] A. Decò and D. M. Frangopol, "Risk assessment of highway bridges under multiple hazards," Journal of Risk Research, vol. 14, no. 9, pp. 1057-1089, 2011.

[41] J. Lai, X. Wang, J. Qiu, J. Chen, Z. Hu, and H. Wang, "Extreme deformation characteristics and countermeasures for a tunnel in difficult grounds in southern Shaanxi, China," Environmental Earth Sciences, vol. 77, no. 19, pp. 1-14, 2018.

[42] J. Qiu, T. Yang, X. Wang, and G. Zhang, "Review of the flame retardancy on highway tunnel asphalt pavement," Construction and Building Materials, vol. 195, no. 19, pp. 468-482, 2019. 


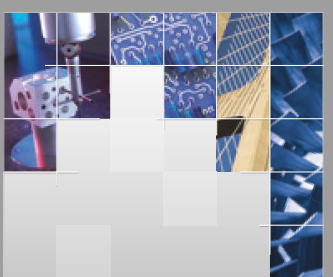

\section{Enfincering}
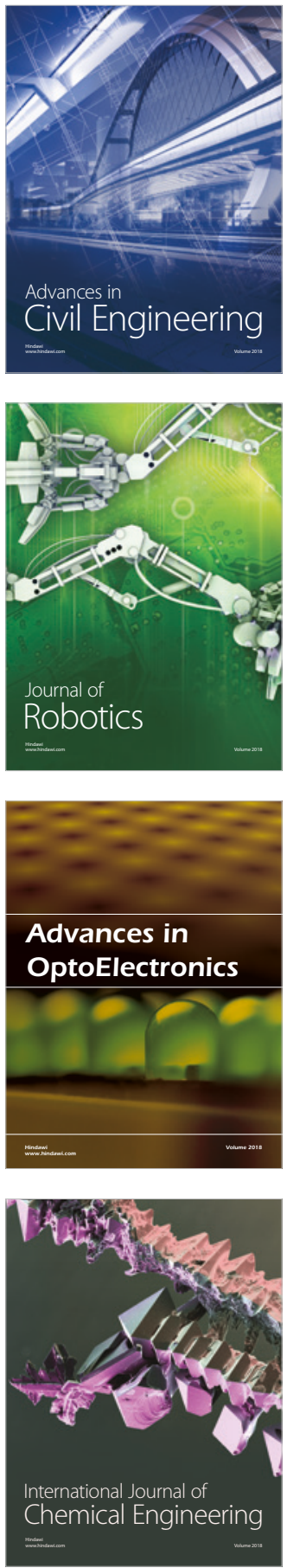

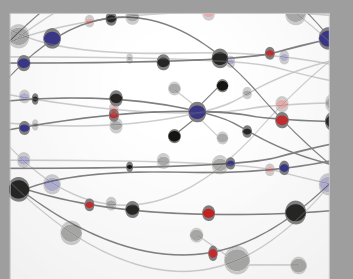

\section{Rotating \\ Machinery}

The Scientific World Journal

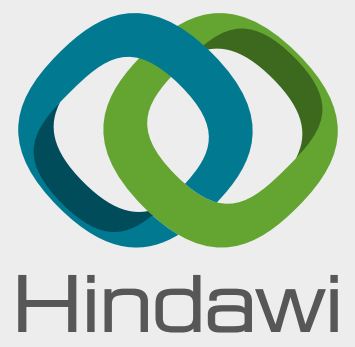

Submit your manuscripts at

www.hindawi.com
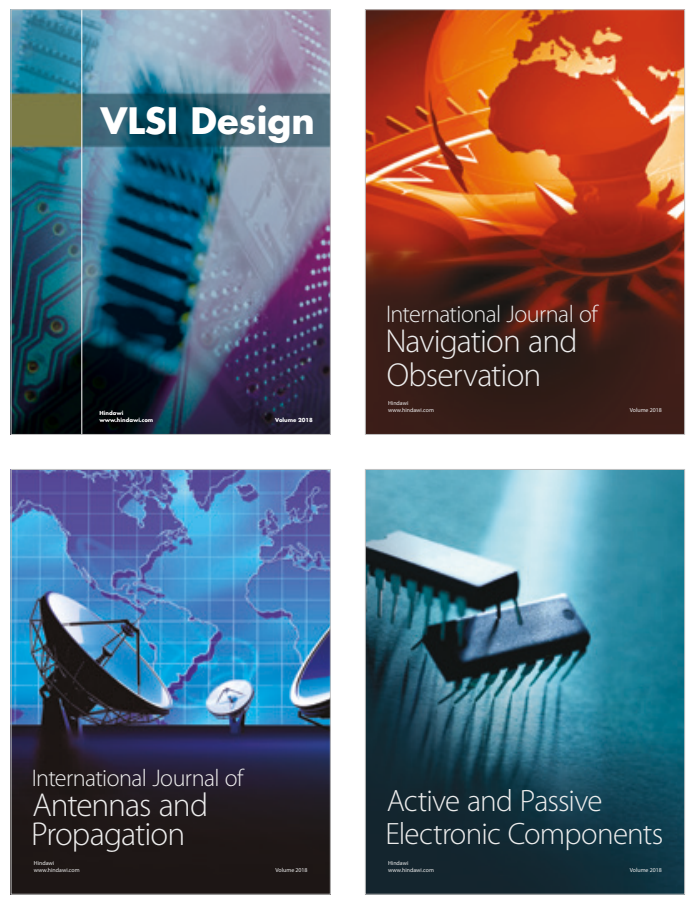
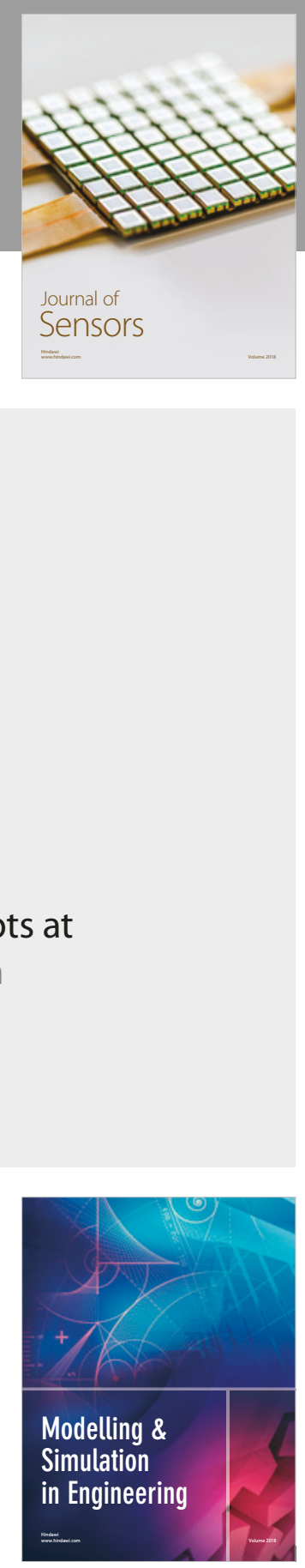

\section{Advances \\ Multimedia}
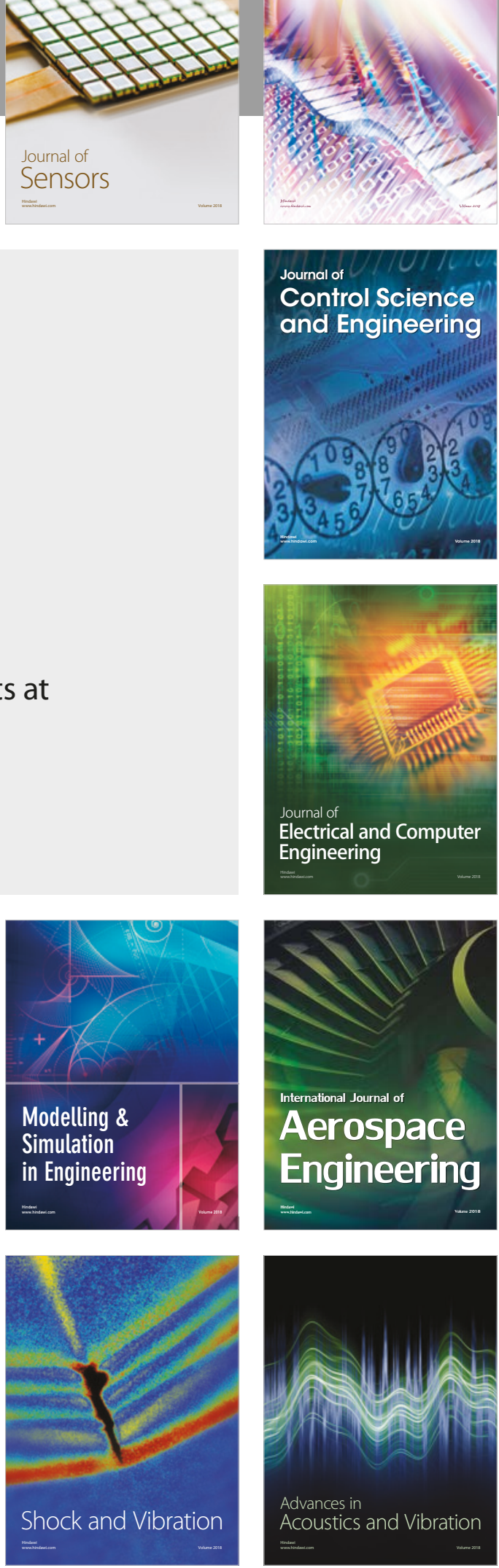